\title{
AN INVESTIGATION ABOUT EFFECTS OF FLUID-STRUCTURE-SOIL INTERACTION ON RESPONSE MODIFICATION COEFFICIENT OF ELEVATED CONCRETE TANKS
}

\author{
Mirtaha HASHEMI, Khosrow BARGI \\ University of Tehran, Tehran, Iran (the Islamic Republic of)
}

Received 23 November 2015; accepted 05 February 2016

\begin{abstract}
This paper aims to observe effects of fluid-structure-soil interactions on the response modification coefficient of elevated concrete tanks with frame and shaft supporting systems. Because of weaknesses and failures of elevated tanks that have been reported in recent earthquakes and importance of optimum and resistant design and also better seismic performance of these structures, it is essential to investigate on the response modification coefficient of elevated concrete tanks. In this paper, the response modification coefficient has been evaluated by using the numerical modeling. The method of research is a case study. The models have been subjected to an ensemble of important earthquake ground motions. The effects of soilstructure interactions and fluid-structure interactions on seismic behavior of the elevated concrete tanks have been modeled by the equivalent springs and Housner's method, respectively. Dynamic response of the elevated tanks has been considered by using the nonlinear time history analysis and the discrete plastic hinge approach. Finally, the effects of fluid-structure-soil interactions on the response modification coefficient of the elevated concrete tanks have been discussed by considering results of the analyses. It has been concluded that the codes may underestimate base seismic forces for some seismic regions and some subsoil classes.
\end{abstract}

Keywords: elevated concrete tanks, fluid-structure-soil interaction, response modification coefficient, earthquake ground motion, nonlinear time history analysis, discrete plastic hinge.

\section{Introduction}

Water supply is very essential to put out a fire and other vital needs for example drinking water especially after earthquakes. Thus, elevated tanks should remain functional during earthquakes. Elevated tanks are heavy structures that most of their masses (container) being lumped at a relatively large distance (between 10 $\mathrm{m}$ and $30 \mathrm{~m}$ ) from the foundation. It is very important to consider earthquake forces and ductility in these structures. Concept of the response modification coefficient is used for considering ductility in the design and evaluation of base seismic forces.

The effect of the fluid-structure-soil interaction is one of several important reasons to describe the poor seismic performance of elevated tanks during current earthquakes (Dutta et al. 2004, 2009; Livaoglu, Dogangun 2006, 2007). How to behavior of the fluid into containers and the subsoil are important and effective for evaluation of the response modification coefficient. Therefore, it must be studied until elevated tanks remain safety and operational, in future earthquakes. General methods of the design in the codes usually secure stiffness and strength of a structure by limiting displacements and without concentrating on target conditions of elements. In these methods, there is no guarantee to utilize the ductile capacity of all elements. In this paper, it has been tried to consider these points and also used the discrete plastic hinge 
approach which is computationally more efficient (Wilson 2003).

It has been evaluated the structural response factor of reinforced concrete chimneys by using the discrete plastic hinge approach (Wilson 2003). It has been evaluated the response modification factor of elevated concrete tanks without considering any soil-structure interactions (Masoudi et al. 2012). In other words, it has been assumed to be the rigid subsoil.

\section{Models characteristics of elevated concrete tanks}

Main components of elevated tanks for modeling divided into three categories: the fluid that is maintained in a container, the supporting system and the foundation. There are two types of supporting systems: frame and shaft supporting systems. These supporting systems have different structural properties which are described in the following subsections. Therefore, those have been modeled separately. The method of this research is a case study. The selected models are similar to the practical elevated concrete tanks. Two elevated concrete tanks with a $25 \mathrm{~m}$ height have been used for a numerical modeling.

Vertical and horizontal members of the supporting system are modeled as two-nodded elements with hinges at the beginning of them. Plastic rotation will occur in the hinges if moment of the section reaches yield moment. Properties of the hinges have been tried to estimate by considering valid literature which are described in this section and its subsections. The effective stiffness value for modeling of stiffness properties of the cracked supporting systems is assumed $0.7 E I_{g}$ (Paulay, Priestley 1992). The yield and ultimate strengths of steel are $360 \mathrm{MPa}$ and $520 \mathrm{MPa}$, respectively. The ultimate compressive strength of the section is $30 \mathrm{MPa}$. The compressive and tensile strain limit of the section is assumed 0.002 .

In this paper, a cylinder container (tank) with a volume of $800 \mathrm{~m}^{3}$ has been assumed for the modeling. Aspect ratios and thick concrete of this container allow considering a rigid container model (Priestley et al. 1986). Therefore, the container is assumed to be a rigid structure which has been modeled by rigid members. Furthermore, mass of the structure is equally distributed at the end of the rigid members (Dutta et al. 2004). It should be noted that this research focuses on the nonlinear response of supporting systems rather than the container.

\subsection{Elevated concrete tanks with shaft supporting systems}

Elevated concrete tanks with a shaft supporting system are determinate structures. It will collapse by forming the first plastic hinge in any location along the shaft height, because only path of transmitting lateral forces is failed. The shear design of the shaft supporting system is done such that brittle or shear failure would not occur. External and internal diameters of the shaft are $7 \mathrm{~m}$ and $6.5 \mathrm{~m}$, respectively. In the model, length of the supporting system has been divided into ten elements (Wilson 2003; Masoudi et al. 2012) with a hinge at the beginning of them. It has been shown in Figure 1. A plastic hinge length equal to 0.2 of the average diameter of the shaft has been considered (Moller, Rubinstein 1992). It should be noted that the method of Moller and Rubinstein has been used to calculate the moment-curvature diagram of the reinforced concrete sections (Moller, Rubinstein 1992).

\subsection{Elevated concrete tanks with frame supporting systems}

Large redundancy and accrete connections in a frame supporting system result in a more appropriate performance under seismic forces than a shaft supporting system. A frame supporting system does not behave like building frames its main reason is more uniform distribution of the mass along buildings height than elevated tanks. A rigid flexural frame has been used in the present paper. The strong column-weak beam design approach has been selected and also assumed that the columns do not suffer plastic deformation. Therefore, elastic-plastic hinges are placed at the end of beams. It has been shown in Figure 2. A plastic hinge length equal to 0.5 of height of the beam section has been considered for the modeling (Westergaard 1993).

The frame supporting system has four stories with a $7 \mathrm{~m}$ height in the first story and $6 \mathrm{~m}$ height in the other stories. Dimensions of the columns are $0.8 \times 0.8$ $\mathrm{m}$ and dimensions of the circumferential beams are $0.8 \times 0.6 \mathrm{~m}$ and also dimensions of radial beams in the last story which are connected to a concrete slab are $0.8 \times 0.5 \mathrm{~m}$. The thickness of the slab is $0.25 \mathrm{~m}$. Diameters of the frame supporting system are $12 \mathrm{~m}$ and 7 $\mathrm{m}$ in the first and last stories. Figure 3 shows a horizontal section of the frame supporting system in the last story. 


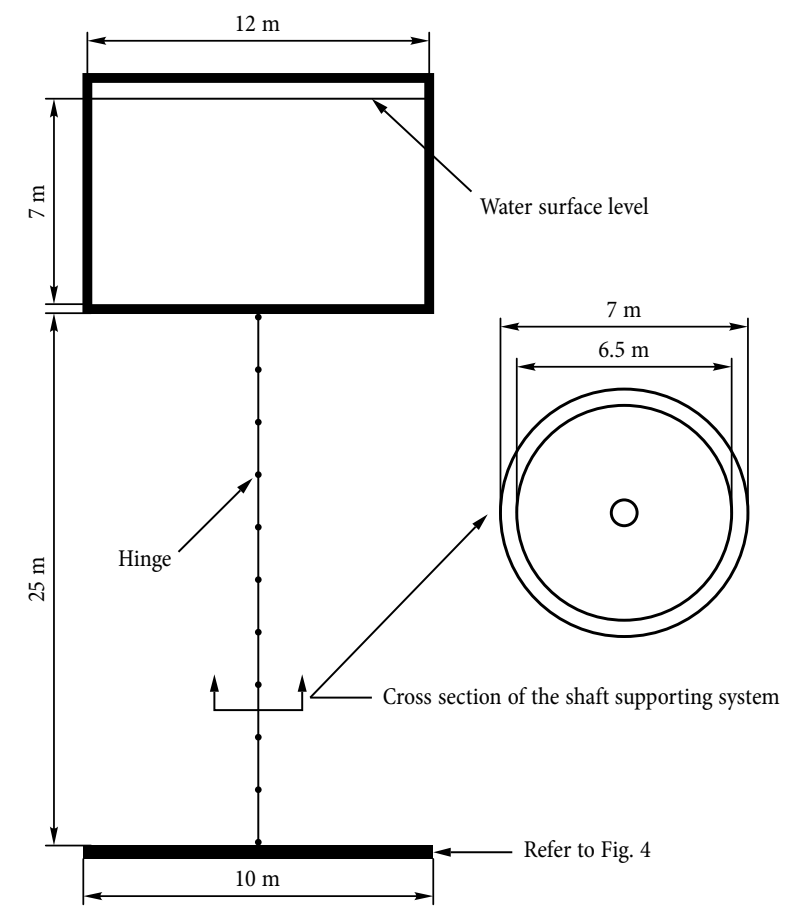

Fig. 1. Location of the hinges in the shaft supporting system

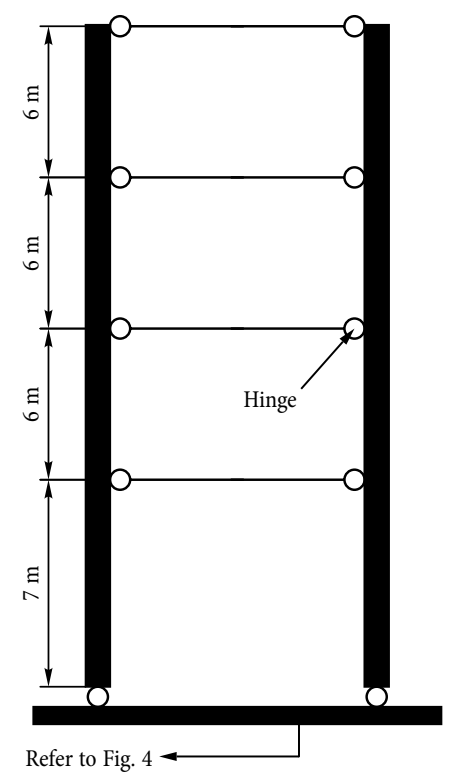

Fig. 2. Location of the hinges in the frame supporting system

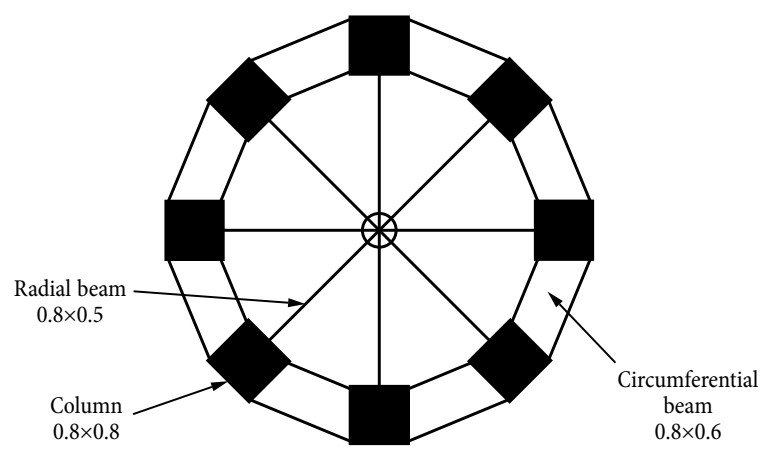

Fig. 3. The section of the frame supporting system in the last story

\section{Effects of fluid-structure-soil interactions on elevated tanks}

Researchers have been proposed different methods or techniques for considering interactions of soils and fluids on elevated tanks. The simplified procedures have been used to consider these interactions in the present paper. Modeling of the fluid-structure-soil interaction effects on the elevated concrete tanks has been carried out by the software (SAP2000 2010). Damping values are taken as $5 \%$ and $0.5 \%$ for the impulsive mode and the convective mode, respectively (ACI 371R-08:2008; ASCE/SEI 7-10:2010). The chosen damping values have been verified for the subsoil classes in the literatures (Livaoglu, Dogangun 2006).

Note, in this paper the finite element method has not been used to consider the fluid-structure-soil interactions because this method requires a significant time for running analysis models while there is a negligible advantage in this method compared to its complexity (Livaoglu, Dogangun 2006; Sezen et al. 2008). Furthermore, the added mass approach has not been used because an extensive study on concrete elevated tanks shows negligible differences in this approach and the simplified models (Dutta et al. 2001).

\subsection{Soil-structure interactions}

Elevated tanks are supported on a relatively small area. It has generally been recognized that the soil-structure interactions can affect the response of structures, especially for structures on relatively flexible soils (not very rigid) and located in active seismic zones (Livaoglu, Dogangun 2006). Neglecting soil-flexibility may cause overlooking the possibility of occurring axial tension in columns and wrong assessment of torsional vulnerability of the supporting system structures (Dutta et al. 2004). Therefore, considering soil-structure interactions is very important to obtain a idealized model and more accurate results. Researchers have been proposed different methods to assess the effect of soil-structure interactions for example the finite element method, the massless foundation (Wilson 2002) and the equivalent springs.

In this paper, the selected method is the equivalent springs which has been proposed in the literature (Gazetas 1991) and the code (FEMA 368/369:2000). The model has been illustrated in Figure $4 . K_{x}, K_{\theta}$ and $K_{t}$ represent the equivalent horizontal translational, rocking and horizontal stiffness of a foundation, re- 


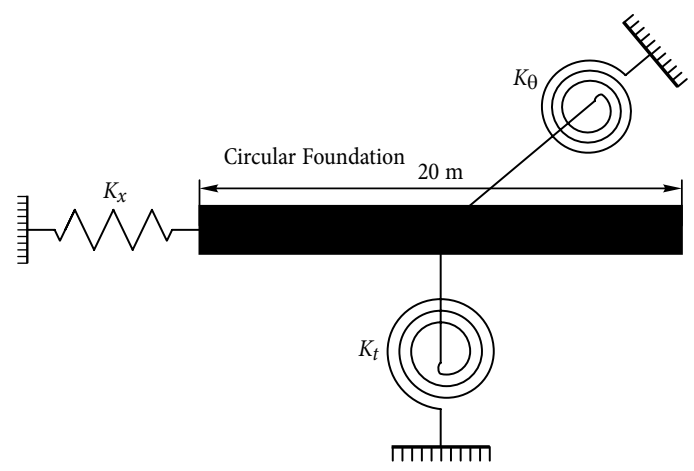

Fig. 4. The model for considering soil-structure interactions

spectively. These are attached to the rigid circular foundation center with a $10 \mathrm{~m}$ radius which is supported on a semi-infinite homogeneous half-space. The expressions are as follows:

$$
\begin{aligned}
& K_{x}=\frac{8 \alpha_{x} G r}{2-v} ; \\
& K_{\theta}=\frac{8 \alpha_{\theta} G r^{3}}{3(1-v)} ; \\
& K_{t}=6 \alpha_{t} G r^{3} .
\end{aligned}
$$

Where $\alpha_{x}, \alpha_{\theta}$ and $\alpha_{t}$ are the dimensionless coefficients, $r$ is the radius of a foundation, $G$ is the shear modulus of the soil, and $v$ is the soil Poisson's ratio.

\subsection{Fluid-structure interactions}

Different methods have been proposed to assess the effect of fluid-structure interactions for example the spring-mass models, the finite element method and the added mass approach (Dogangun et al. 1996). In this paper, the fluid-structure interactions have been considered by a two-mass model as suggested by Housner (1963). It has been shown in Figure 5. The fluid into the container is modeled by an impulsive mass $\left(M_{i} \approx 450\right.$ ton) that is rigidly attached to the container wall at a height of $\left(H_{i} \approx 2.75 \mathrm{~m}\right)$ and a con-

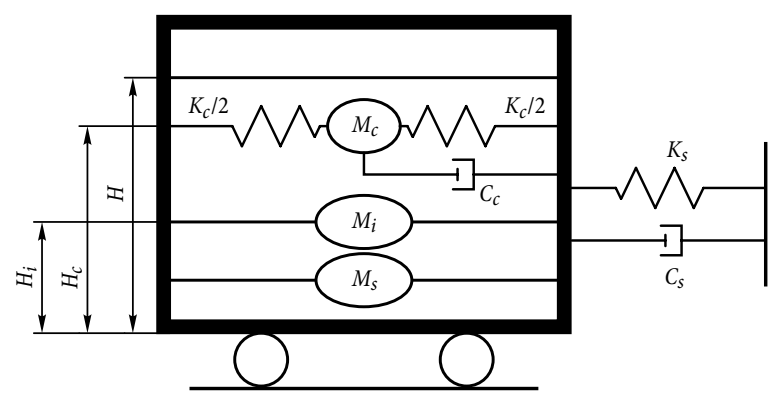

Fig. 5. The model for considering the effect of fluid-structure interactions vective mass $\left(M_{c} \approx 395\right.$ ton) that is connected to the wall through the springs of stiffness $\left(K_{c} \approx 1175 \mathrm{kN} / \mathrm{m}\right)$ at a height of $\left(H_{c} \approx 4.5 \mathrm{~m}\right)$. Higher modes of sloshing for the elevated tanks have negligible influence on forces exerted on the container (Haroun, Ellaithy 1985; Livaoglu, Dogangun 2005). Therefore, they are not regarded in analyses of this study. $M_{s}, K_{s}, C_{s}$ and $C_{c}$ are the mass of supporting systems, the stiffness of supporting systems, the damping of supporting systems and the damping of convective motions, respectively. The expressions are as follows (Epstein 1976):

$$
\begin{gathered}
M_{i}=M \frac{\tan h(1.74 R / H)}{1.74 R / H} ; \\
M_{c}=0.318 M \frac{\tan h(1.84 H / R)}{H / R} ; \\
K_{c}=1.84 M_{c} \frac{g}{R} \tan h\left(\frac{1.84 H}{R}\right) ; \\
\left.H_{c}=\left[\begin{array}{c}
\cos h(1.84 H / R)-1 \\
1.84 H / R
\end{array}\right] H ; \sinh (1.84 H / R)\right] \\
H_{i}=\frac{3}{8} H,
\end{gathered}
$$

where $M$ and $H$ indicate the total mass of the fluid and the depth of water at any instant of time, respectively, $R$ denotes the radius of a container and $g$ is the acceleration due to gravity.

\section{Approach for calculation of the response modification coefficient}

Following formula has been used for calculation of the response modification coefficient (ATC-306:1978; FEMA 450:2004):

$$
R=I F \times b / c .
$$

where $I F$ is the importance factor (it is assumed 1.25 in this paper), $b=a_{f} / a_{e}$ is dependent on the design, $c=a_{2475} / a_{475}$ is the acceleration ratio that depends on the seismicity of the site (it is assumed that $c$ varies from 1.5 to 3 for high and low seismic regions, respectively (Masoudi et al. 2012; ATC-3-06:1978; FEMA 450:2004). $a_{2475}$ and $a_{475}$ is the peak ground acceleration (PGA) of the design maximum earthquake with a return period of 2475 years (it associates with the structural stability limit state) and the design basis earthquake with a return period of 475 years (it asso- 
ciates with the serviceability limit state), respectively. $a_{f}$ (the failure acceleration) is the PGA of a record which it is scaled to the extent that one of the hinges is reached the ultimate rotation capacity and $a_{e}$ (the elastic acceleration) is the PGA of a record which it is scaled to the extent that one of the hinges is reached the first yield.

\section{Results}

The nonlinear response of elevated tanks can be considered by means of the pushover analysis or the dynamic analysis. The pushover analysis may fail to estimate the real dynamic behavior of the structure in many cases (D'Ambrisi et al. 2012; Pena et al. 2010). Furthermore, the results of analyses show that effects of higher modes (especially until mode 4) on the response of the elevated tanks are apparent and significant. Sum of the first nine modes partnership is more than $90 \%$. Thus, the dynamic response of elevated tanks has been studied by the method of the nonlinear time history analysis that it can consider effects of higher modes.

The peak ground acceleration has been assumed $0.35 \mathrm{~g}$. Five different subsoil classes and also rigid soil conditions (Eurocode-8:2003) with full and empty containers have been applied for evaluation of the effects of fluid-structure-soil interactions. The threedimensional models have been subjected to seven important earthquake records, i.e. Loma Prieta, Northridge, Elcentro, Tabas, Imperial Valley, Landers and Morgan Hill.

Minimum ratios of $b$ which is obtained from the different records have been used for calculation of the response modification coefficient because those lead to smaller and critical coefficients. Minimum ratios of $b$ have been obtained in the both models and the different subsoil conditions with full and empty containers. Those have been showed in Table 1 and Table 2 .

\section{Discussion of the analysis results}

It is seen in Table 1 and Table 2 that considering the soil-structure interactions lead to decrease (in subsoil classes A, B and C) and increase (in subsoil classes D and $\mathrm{E}$ ) the ratio of $b$. Minimum and maximum ratios of $b$ have been obtain in conditions of empty and full containers, respectively. Results of analyses are close in the both types of supporting systems. Table 1 and Table 2 also show that considering the fluid-structure-
Table 1. Results of the response modification coefficient for the frame supporting system

\begin{tabular}{|l|c|c|c|c|c|c|}
\hline \multirow{2}{*}{$\begin{array}{l}\text { Type of } \\
\text { container }\end{array}$} & \multirow{2}{*}{$\begin{array}{c}\text { Type of } \\
\text { subsoil }\end{array}$} & $a_{f} / a_{e}$ & \multicolumn{5}{|c|}{$c$} \\
\cline { 4 - 7 } $\begin{array}{l}\text { Full } \\
\text { container }\end{array}$ & Rigid & 3.6 & 3 & 2.25 & 1.8 & 1.5 \\
\hline & $\mathrm{A}$ & 3.5 & 2.91 & 2.18 & 1.75 & 1.45 \\
\hline & $\mathrm{B}$ & 3.1 & 2.58 & 1.93 & 1.55 & 1.29 \\
\hline & $\mathrm{C}$ & 2.85 & 2.37 & 1.78 & 1.42 & 1.18 \\
\hline & $\mathrm{D}$ & 4.05 & 3.37 & 2.53 & 2.02 & 1.68 \\
\hline & $\mathrm{E}$ & 4.65 & 3.85 & 2.9 & 2.32 & 1.93 \\
\hline & $\mathrm{B}$ & & & & & \\
\hline $\begin{array}{l}\text { Empty } \\
\text { container }\end{array}$ & Rigid & 3.35 & 2.79 & 2.09 & 1.67 & 1.39 \\
\hline & $\mathrm{A}$ & 3.3 & 2.75 & 2.06 & 1.65 & 1.37 \\
\hline & $\mathrm{B}$ & 2.9 & 2.41 & 1.81 & 1.45 & 1.2 \\
\hline & $\mathrm{C}$ & 2.6 & 2.16 & 1.62 & 1.3 & 1.08 \\
\hline & $\mathrm{D}$ & 3.8 & 3.16 & 2.37 & 1.9 & 1.58 \\
\hline & $\mathrm{E}$ & 4.4 & 3.66 & 2.75 & 2.2 & 1.83 \\
\hline
\end{tabular}

Table 2. Results of the response modification coefficient for the shaft supporting system

\begin{tabular}{|l|c|c|c|c|c|c|}
\hline \multirow{2}{*}{$\begin{array}{l}\text { Type of } \\
\text { container }\end{array}$} & \multirow{2}{*}{$\begin{array}{c}\text { Type of } \\
\text { subsoil }\end{array}$} & $a_{f} / a_{e}$ & \multicolumn{5}{|c|}{$\mathrm{c}$} \\
\cline { 4 - 7 } $\begin{array}{l}\text { Full } \\
\text { container }\end{array}$ & Rigid & 3.75 & 3.12 & 2.3 .4 & 1.87 & 1.56 \\
\hline & $\mathrm{A}$ & 3.6 & 3 & 2.25 & 1.8 & 1.5 \\
\hline & $\mathrm{B}$ & 3.2 & 2.66 & 2 & 1.6 & 1.33 \\
\hline & $\mathrm{C}$ & 2.9 & 2.41 & 1.81 & 1.45 & 1.2 \\
\hline & $\mathrm{D}$ & 4.2 & 3.5 & 2.62 & 2.1 & 1.75 \\
\hline & $\mathrm{E}$ & 4.85 & 4.04 & 3.03 & 2.42 & 2.02 \\
\hline & $\mathrm{Rigid}$ & 3.2 & 2.66 & 2 & 1.6 & 1.33 \\
\hline $\begin{array}{l}\text { Empty } \\
\text { container }\end{array}$ & $\mathrm{A}$ & 3.1 & 2.58 & 1.93 & 1.55 & 1.29 \\
\hline & $\mathrm{B}$ & 2.75 & 2.29 & 1.71 & 1.37 & 1.14 \\
\hline & $\mathrm{C}$ & 2.55 & 2.12 & 1.59 & 1.27 & 1.06 \\
\hline & $\mathrm{D}$ & 3.75 & 3.12 & 2.34 & 1.87 & 1.56 \\
\hline & $\mathrm{E}$ & 4.3 & 3.58 & 2.68 & 2.15 & 1.79 \\
\hline
\end{tabular}

soil interaction especially the soil-structure interaction has noticeable effects on the results. These effects are smaller in the stiffer subsoil " $\mathrm{A}$ " in comparison to the without interaction subsoil (rigid subsoil). Considering the fluid-structure interaction (full container) leads to bigger response modification coefficients. Therefore, the empty tank is the critical condition to evaluate the response modification coefficient because the empty tank leads to smaller response modification 
coefficients and also the smaller response modification coefficient leads to the bigger seismic base shear $(V)$ because there is a relation between $V$ and $1 / R$ (ACI 371R-08:2008).

The response modification coefficient has been obtained around range 1-3.9. The response modification coefficient of elevated tanks is generally recommended to be around range $2-3$ by the seismic codes (FEMA 368/369:2000; ACI 371R-98:1995; Eurocode-8:2003). It means that the codes may underestimate base seismic forces for some seismic regions and some subsoil classes especially if $c$ is considered larger than 2.5. The results of this section show that ductility of elevated tanks should be considered with caution and accurate. It should be noted that this paper is a case study by using the numerical modeling. So that, it is recommended to consider more models for example a structure with different height of supporting systems and shape of containers to come up with a solid recommendation for the response modification coefficient of elevated concrete tanks.

\section{Conclusions}

In this paper, two elevated concrete tanks with shaft and frame supporting systems were modeled numerically and were subjected to seven earthquake records. The structures were designed by considering target condition of the elements and formation of the plastic hinges. The dynamic response of elevated tanks was studied by using nonlinear time history analyses and the discrete plastic hinge approach. Finally, the response modification coefficient of the elevated concrete tanks was evaluated by considering the fluidstructure-soil interactions and the nonlinear behavior of the structures. The results indicated:

- The response modification coefficient was obtained around in the range 1-3.9.

- The fluid-structure-soil interaction especially the soil-structure interaction affects considerably on the results. These effects are smaller in stiffer subsoil "A" in comparison to the without interaction subsoil (rigid subsoil).

- The fluid-structure interaction leads to bigger response modification coefficient. Therefore, the empty tank is the critical condition.

- The response modification coefficient of elevated tanks is generally recommended to be in the range $2-3$ by the current seismic codes.
It means that the codes may underestimate the base seismic shear for some seismic regions and some subsoil classes. Therefore, ductility of elevated tanks should be considered with caution and accurate.

This paper is a case study by using the numerical modeling. Therefore, it is recommended to consider more computational models for evaluation of the response modification coefficient of elevated concrete tanks.

\section{References}

ACI 371R-08:2008. Guide for the Analysis, Design and Construction of Elevated Concrete and Composite Steel-concrete Water Storage Tanks. American Concrete Institute.

ASCE/SEI 7-10:2010. Minimum Design Loads for Buildings and other Structures. Structural Engineering Institute, American Society of Civil Engineers.

ATC-3-06:1978. Tentative Provisions for the Development of Seismic Regulations for Buildings. Applied Technology Council.

ACI 371R-98:1995. Guide to the Analysis Design and Construction of Concrete-pedestal Water Tower. American Concrete Institute.

Dutta, S.; Mandal, A.; Dutta, S. C. 2004. Soil-structure interaction in dynamic behavior of elevated tanks with alternate frame supporting system configurations, Journal of Sound and Vibration 277: 825-853.

http://dx.doi.org/10.1016/j.jsv.2003.09.007

Dutta, S. C.; Dutta, S.; Roy, R. 2009. Dynamic behavior of R/C elevated tanks with soil-structure interaction, Engineering Structures 31: 2617-2629.

http://dx.doi.org/10.1016/j.engstruct.2009.06.010

Dutta, S. C.; Jain, S. K.; Murty, C. V. R. 2001. Inelastic seismic torsional behavior of elevated tanks, Journal of Sound and Vibration 242: 151-167.

http://dx.doi.org/10.1006/jsvi.2000.3343

Dogangun, A.; Durmus, A.; Ayvaz, Y. 1996. Finite element analysis of seismic response of rectangular tanks using added mass and lagrangian approach, in Proceedings of the Second International Conference on Civil Engineering Computer Applications Research and Practice, Vol. 1, 6-8 April 1996, Bahrain, Iran, 371-379.

D'Ambrisi, A.; Mariani, V.; Mezzi, M. 2012. Seismic assessment of a historical masonry tower with nonlinear static and dynamic analyses tuned on ambient vibration tests, Engineering Structures 36: 210-219.

Epstein, H. I. 1976. Seismic design of liquid-storage tanks, ASCE Journal of Structural Division 102: 1659-1673.

Eurocode-8:2003. Design of Structures for Earthquake Resistance_Part 1. 1: General rules_Seismic action and general requirements for structures- Part 4: Silos, tanks and pipelines. European Committee for Standardization.

FEMA 368/369:2000. NEHRP Recommended Provisions for New Buildings and Other Structures, Part 1: Provision and Part 2: Commentary. Federal Emergency Management Agency. 
FEMA 450:2004. NEHRP Recommended Provisions for Seismic Regulations for New Buildings and other Structures. Federal Emergency Management Agency.

Gazetas, G. 1991. Formulas and charts for impedances of surface and embedded foundations, Journal of Geotechnical Engineering, American Society of Civil Engineers 117(9): 1363-1381.

http://dx.doi.org/10.1061/(ASCE)0733-9410(1991)117:9(1363)

Housner, G. W. 1963. The dynamic behavior of water tanks, Bulletin of the Seismological Society of American 53: 381-387.

Haroun, M. A.; Ellaithy, M. H. 1985. Seismically induced fluid forces on elevated tanks, Journal of Technical Topics in Civil Engineering 111: 1-15.

Livaoglu, R.; Dogangun, A. 2006. Simplified seismic analysis procedures for elevated tanks considering fluid-structuresoil interaction, Journal Fluids and Structures 22: 421-439. http://dx.doi.org/10.1016/j.jfluidstructs.2005.12.004

Livaoglu, R.; Dogangun, A. 2007. Effect of foundation embedment on seismic behavior of elevated tanks considering fluid-structure-soil interaction, Soil Dynamics and Earthquake Engineering 27: 855-863.

http://dx.doi.org/10.1016/j.soildyn.2007.01.008

Livaoglu, R.; Dogangun, A. 2005. Seismic evaluation of fluidelevated tank foundation/soil systems in frequency domain, Structural Engineering and Mechanics 21: 101-119. http://dx.doi.org/10.12989/sem.2005.21.1.101

Masoudi, M.; Eshghi, S.; Ghafory-ashtiany, M. 2012. Evaluation of response modification factor (R) of elevated concrete tanks, Engineering Structures 39: 199-209. http://dx.doi.org/10.1016/j.engstruct.2012.02.015

Moller, O.; Rubinstein, M. 1992. Reliability-based design of R/C water tank structures under seismic action, Earthquake Engineering \& Structural Dynamics 21: 665-678. http://dx.doi.org/10.1002/eqe.4290210802
Paulay, T.; Priestley, M. J. N. 1992. Seismic design of reinforced concrete and masonry buildings. New York: John Wiley \& Sons. http://dx.doi.org/10.1002/9780470172841

Priestley, M. J. N.; Davidson, B. J.; Honey, G. D.; Hopkins, D. C.; Martin, R. J.; Ramsey, G., et al. 1986. Seismic design of storage tanks. Recommendation of a study group of the New Zealand National Society for Earthquake Engineering. Wellington, New Zealand: New Zealand Society for Earthquake Engineering.

Pena, F.; Lourenco, P. B.; Mendes, N.; Oliveira, D. V. 2010. Numerical models for the seismic assessment of a masonry tower, Engineering Structures 32: 1466-1478.

http://dx.doi.org/10.1016/j.engstruct.2010.01.027

SAP2000. 2010. Integrated Software for Structural Analysis \& Design. Berkeley, CA: Computers and Structures Inc.

Sezen, H.; Livaoglu, R.; Dogangun, A. 2008. Dynamic analysis and seismic performance evaluation of above-ground liquid-containing tanks, Engineering Structures 30: 794-803. http://dx.doi.org/10.1016/j.engstruct.2007.05.002

Wilson, J. L. 2003. Earthquake response of tall reinforced concrete chimneys, Engineering Structures 25: 11-24. http://dx.doi.org/10.1016/S0141-0296(02)00098-6

Westergaard, H. M. 1993. Water pressures on dams during earthquakes, Transactions of the American Society of Civil Engineering 98: 418-433.

Wilson, E. L. 2002. Three-dimensional static and dynamic analysis of structures_a physical approach with emphasis on earthquake engineering. $3^{\text {rd }}$ ed. Berkeley, CA: Computers and Structures Inc.

Mirtaha HASHEMI is a formerly graduate student with the degree of master of science in civil engineering - structural engineering from School of civil engineering, College of engineering, University of Tehran, Tehran 11155-4563, Iran. Research interests: civil engineering, earthquake engineering, marine works and hydraulic structures, analysis and design of structures, mechanical stability.

Khosrow BARGI was graduated from Paris, France, 1986. And now he is a professor and teacher at School of Civil Engineering, College of engineering, University of Tehran, Tehran 11155-4563, Iran. Research interests: civil engineering, earthquake engineering, marine works and hydraulic structures, analysis and design of structures. 